\title{
$\begin{array}{ll}\text { Research Square } & \begin{array}{l}\text { Preprints are preliminary reports that have not undergone peer review. } \\ \text { They should not be considered conclusive, used to inform clinical practice, } \\ \text { or referenced by the media as validated information. }\end{array}\end{array}$
}

\section{Effect of SGLT-2 Inhibitors on Cardiovascular Outcomes Among Patients With Heart Failure and Type 2 Diabetes Mellitus: A Systemic Review and Meta- Analysis of Randomized Controlled Trials}

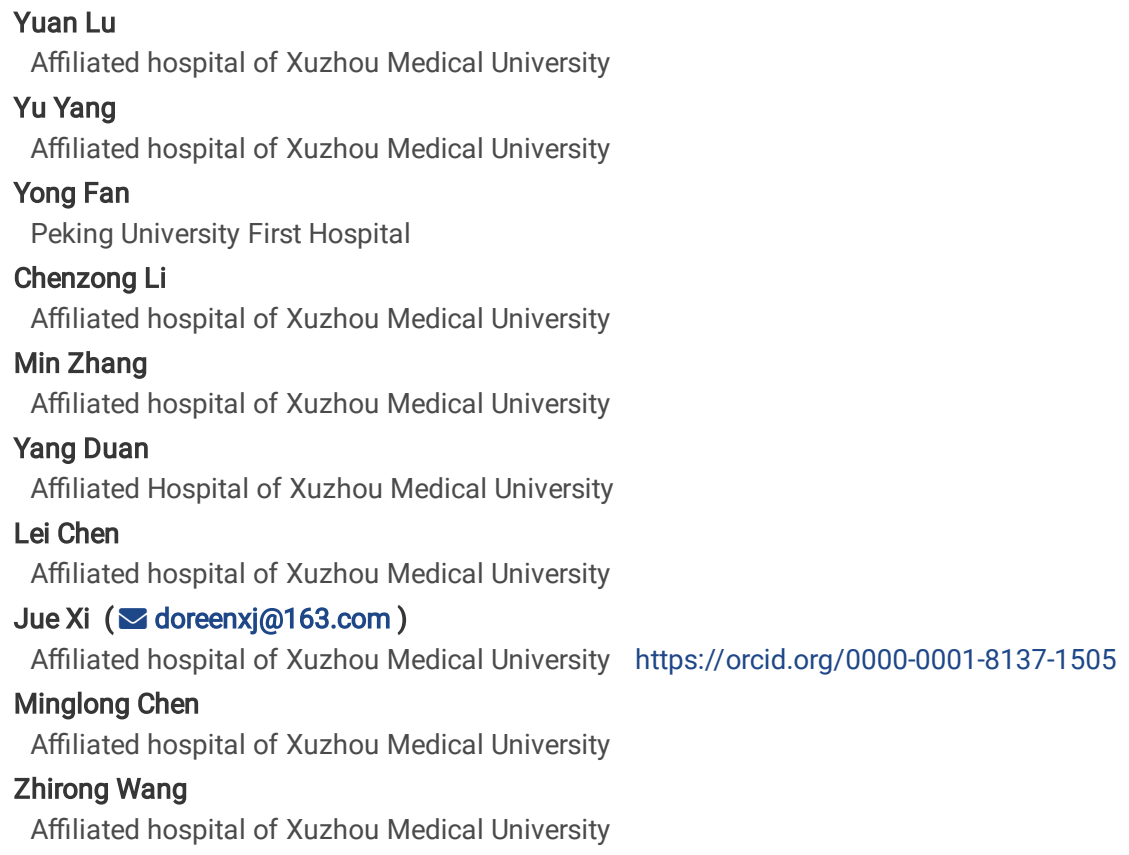




\section{Abstract \\ Background}

Sodium-glucose cotransporter-2 inhibitors (SGLT-2i) are significantly effective in reducing cardiovascular events in patients with type 2 diabetes mellitus (T2DM). However, the magnitude of the effect of SGLT-2i on cardiovascular outcomes in established heart failure (HF) patients with T2DM remains undefined.

\section{Methods}

We systematically searched the PubMed, Embase, Cochrane Central and Web of Science databases for articles published prior to 09 April 2020 to identify randomized controlled trials that compared SGLT-2i with placebo in patients with heart failure concomitant with T2DM. Efficacy outcomes included the composite of cardiovascular death (CVD) or hospitalization for heart failure (HHF), individual CVD, individual HHF, and all-cause mortality (ACM). Hazard ratios (HRs) with $95 \%$ confidence intervals $(95 \% \mathrm{Cls}$ ) were pooled across trials by using the generic inverse variance method. Sensitivity analyses were conducted by excluding specific studies or using risk ratios (RRs) with $95 \% \mathrm{Cls}$ as measures of the effect size. Serious adverse events served as safety outcomes.

\section{Results}

A total of 5 large trials comprising 6945 patients with HF and T2DM were enrolled. Pooled data demonstrated that SGLT-2i significantly reduced the risk for the primary composite outcome of CVD or HHF by $13 \%$ (HR: $0.87,95 \% \mathrm{Cl}: 0.83-0.91, \mathrm{I}^{2}: 0 \%, \mathrm{P}<0.00001$ ) in patients with HF concomitant with T2DM. Similarly, the use of SGLT-2i was associated with a statistically significant $14 \%$ reduction in HHF (pooled HR: $0.86,95 \%$ Cl: $0.81-0.91, \mathrm{I}^{2}: 0 \%, \mathrm{P}<0.00001$ ) and a $10 \%$ reduction in ACM (pooled HR: 0.90, 95\% Cl: $0.86-0.96,12: 16 \%, \mathrm{P}<0.0005)$ but was not significantly associated with a reduction in CVD (HR: $0.91,95 \% \mathrm{Cl}$ : $0.81-1.02, I^{2}: 60 \%, P=0.11$ ). Sensitivity analyses indicted consistent results. Compared with placebo plus standard care, the SGLT-2i group had a lower proportion of serious adverse events (weighted proportions: $44.3 \%$ vs $50.3 \%$; RR $0.88,95 \% \mathrm{Cl} 0.82-0.95, I^{2}: 22 \%, p=0 \cdot 006$ ).

\section{Conclusions}

SGLT-2i significantly reduced the risk of HHF and ACM in a broad range of HF patients concomitant with T2DM. Compared with standard care, SGLT-2i plus standard therapy was associated with a reduction in serious adverse events.

\section{Background}

Heart failure (HF) is a highly prevalent disease with considerable morbidity and mortality. It is estimated that approximately 50 million people are afflicted with this disease worldwide. The disease burden of heart failure represents one of the most serious health concerns facing society today, and it is reported to be the most common diagnosis for hospital admission in people over the age of 65 in some countries[1, 2]. In recent decades, heart failure therapy has developed rapidly, with the PARADIGM-HF trial[3] and the SHIFT trial[4] demonstrating significant reductions in cardiovascular death (CVD) and hospitalization for heart failure (HHF). However, the prognosis of HF remains unsatisfactory, and multiple comorbidities with HF impede therapeutic options. Among patients with established HF, type 2 diabetes mellitus (T2DM) is a fairly common comorbidity that is present in $20-40 \%$ of all patients[5]. Moreover, the presence of T2DM is associated with a significantly worse quality of life and a poor prognosis among patients with HF[6].

Sodium-glucose cotransporter type 2 inhibitors (SGLT-2 inhibitors, SGLT-2i) are a novel class of oral anti-hyperglycaemic drugs used in the management of T2DM that exhibit a unique glucose-lowering effect by inhibiting glucose reabsorption in the proximal renal tubule. The beneficial effect of lowering glucose has already been widely acknowledged for SGLT-2 inhibitors. Impressively, the results from large-scale randomized clinical trials (RCTs), such as the EMPAREG OUTCOME[7] (Empagliflozin Cardiovascular Outcome Event Trial in Type 2 Diabetes Mellitus Patients Removing Excess Glucose) and the CANVAS Program[8] (Canagliflozin Cardiovascular Assessment Study), have further demonstrated the significant benefits of SGLT-2 inhibitors in reducing the risk of cardiovascular outcomes among patients with T2DM. Moreover, sub-analyses revealed that patients with HF at baseline appear to experience greater benefits from those medications $[9,10]$. In addition, a very recent landmark trial (DAPA-HF trial) reported that a SGLT-2 inhibitor, namely, dapagliflozin, markedly reduced mortality and worsening heart failure in patients with heart failure with reduced ejection fraction (HFrEF)[11]. Of note, the benefits were observed in both patients with T2DM and patients without T2DM. These data may greatly usher in a new paradigm in the treatment of heart failure. However, the hypothesis that SGLT-2i might be an effective treatment for a broad range of patients with heart failure, including those with preserved ejection fraction (HFpEF), remains mysterious. Besides, trials assessing the effect of SGLT-2 inhibitors on cardiovascular outcomes may have different scales of effects on clinical outcomes[913]. Consistent with the results of the DAPA-HA trial, the CANVAS Program[10] found that canagliflozin significantly reduced the risk of cardiovascular death or hospitalization for heart failure in patients with HF concomitant with T2DM. Nevertheless, the CREDENCE trial[13] and EMPA-REG OUTCOME trial[12] showed a trend towards cardiovascular advantages in those participants. Thus, based on previous results, we performed this meta-analysis to investigate the pooled effectiveness and safety data of SGLT-2i in a broad range of patients with HF (including HFrEF and HFpEF) who concomitant with T2DM, aiming to provide evidence for the potential use of SGLT-2i to treat heart failure.

\section{Methods}

We followed the Preferred Reporting Items for Systematic Reviews and Meta-Analyses guidelines to conduct this systematic review and meta-analysis[14]. 


\section{Search Strategy and Selection Criteria}

The PubMed, Embase, Cochrane Central Registry of Controlled Trials and Web of Science databases were searched by two independent authors (Y. L and Y.Y) to identify and select relevant articles published prior to 9th April 2020. The following keywords were used as search terms: ("sodium-glucose cotransporter-2 inhibitor" OR "SGLT-2 inhibitor" OR canagliflozin OR dapagliflozin OR empagliflozin OR ertugliflozin OR ipragliflozin OR luseogliflozin OR tofogliflozin) AND (heart failure) AND ("clinical trial" OR trial OR RCT). Additional studies were selected by manually screening the references of articles identified by the search. No restrictions were placed on time or language. Abstracts and presentations from all major conference proceedings between 2018 and 2020 , including the European Society of Cardiology, American Heart Association, American College of Cardiology and American Diabetes Association, were also reviewed.

The titles and abstracts of retrieved articles were reviewed to exclude clearly irrelevant studies, and then, the full texts of the remaining articles were examined. The following predetermined inclusion criteria were used: (1) randomized controlled trials evaluating SGLT-2 inhibitors in patients with T2DM and HF; (2) the key outcomes of interest are the composite of CVD/HHF, individual CVD, individual HHF, and all-cause mortality (ACM); serious adverse events served as safety outcomes; (3) data included hazard ratios (HR, SGLT-2i vs. placebo) estimated by Cox regression analysis in terms of each outcome, or the event frequency, incident rate and sample size for different outcomes in both SGLT-2i and placebo groups were reported; (4) abstracts and conference proceedings from the previous 3 years were included if all relevant data were provided. We excluded studies if they (1) were observational or nonrandomized studies, (2) were reviews or case reports, or (3) used duplicate data.

\section{Data extraction and outcome}

Two independent investigators ( $Y . L$ and $Y$. Y) extracted data according to a predesigned data collection form, which included first author's name, year of publication, drugs, study design, trial identifier and name, age and sex of study participants, intervention and number of patients per arm, median follow-up, median observational time, data regarding cardiovascular events and serious adverse events. A third reviewer (J. X) was consulted to resolve disagreements.

The primary cardiovascular outcome was a composite of CVD (cardiovascular death) or HHF (hospitalization for heart failure), and the secondary outcomes were individual CVD, individual HHF or ACM. The safety outcomes were severe AEs reported by each trial.

\section{Evaluation of Study Quality and Publication Bias}

The quality of the included RCTs was assessed in accordance with the Cochrane quality assessment tool based on seven domains, including (1) randomized sequence generation, (2) allocation concealment, (3) blinding of participants and personnel, (4) blinding of outcome assessment, (5) incomplete outcome data, (6) selective outcome reporting, and (7) other sources of bias. Trials were rated as low risk, high risk, or unclear risk. We also tried to contact the authors of included RCTs to obtain more information for a more comprehensive analysis. To examine publication bias in the results of the meta-analysis, a funnel plot was used.

\section{Statistical Analysis}

Hazard ratios were used as the effect size measure for clinical cardiovascular outcomes, and they were further pooled using the generic inverse variance method[15]. The generic inverse variance method was used to combine log hazard ratios (log HR) and standard errors of the log HR (SElogHR). The log HRs were adjusted for a common set of confounders across studies, such as age, gender, and most importantly, time to events. Heterogeneity between studies was assessed using the Cochrane $Q$ test and $\mathrm{I}^{2}$ statistic. As a guide, $\mathrm{I}^{2}<50 \%$ indicated low heterogeneity, $50-75 \%$ indicated moderate heterogeneity and $>75 \%$ indicated high heterogeneity[16]. Studies with an $\mathrm{I}^{2}$ statistic of $>50 \%$ were considered to have substantial heterogeneity, and a random effects model was used to analyse these studies. Otherwise, a fixed effects model was initially used. We evaluated publication bias using funnel plots. A sensitivity analysis was performed by excluding one study that was only presented at a conference (CREDENCE trial). Alternatively, 3 studies reported the number of clinical outcomes $(\mathrm{n} / \mathrm{N})$ that occurred in both the SGLT-2i and placebo arms. For another sensitivity analysis, we calculated the incidence rate of outcome events and risk ratios (RRs) with data extracted from each RCT. Pooled RRs with 95\% confidence intervals (95\% Cls) were used as the effect size measure for clinical and safety outcomes by using the Mantel-Haenszel fixed effects model. A two-tailed p value of less than 0.05 was considered statistically significant. Statistical analyses were performed using RevMan 5.3 (The Cochrane Collaboration, Copenhagen, Denmark).

\section{Results}

\section{Literature search results and characteristics of identified studies}

The initial search identified a total of 2449 articles, of which 1462 remained after duplicates were removed. After a careful review of the titles/abstracts, 1415 articles were excluded due to not being clinical trials or because they were duplicated studies, and only 47 studies were included in the full-text review for a more detailed evaluation. Ultimately, 5 studies (4 RCTs and 1 conference abstract) met the predefined criteria and were included in this meta-analysis. The details of the search program in this study are shown in Fig. 1.

Of these included 5 studies, two studies assessed canagliflozin, two assessed dapagliflozin, and one assessed empagliflozin. One study (the CREDENCE trial[13]) was described in an abstract but was eligible and included in this meta-analysis because the complete data were available. All of the studies were randomized, double-blind, placebo-controlled trials (the DECLARE-TIMI 58 trial[9], the CANVAS Program[10], the DAPA-HF trial[11], the EMPA-REG OUTCOME trial[12] and the CREDENCE trial[13]), involving a total of 6945 patients with HF and T2DM. Among the enrolled patients, 4686 (67.5\%) were male and 2259 (32.5\%) were female. The median age of patients was typically in the 60 s (ranging from 63.0 to 66.0 years) across all studies, with a median follow-up ranging from 1.5 years to 5.7 years. Table 1 lists the main characteristics of the 5 eligible studies. 
Table 1: Characteristics of included 5 studies in this meta-analysis

\begin{tabular}{|c|c|c|c|c|c|c|c|c|c|c|}
\hline $\begin{array}{l}\text { First } \\
\text { author }\end{array}$ & $\begin{array}{l}\text { Publication } \\
\text { year }\end{array}$ & Drug & $\begin{array}{l}\text { Clinical trial } \\
\text { identifier } \\
\text { (name) }\end{array}$ & $\begin{array}{l}\text { Total } \\
\text { Num } \\
\text { with } \\
\text { HF- } \\
\text { T2DM }\end{array}$ & $\begin{array}{l}\mathrm{HF} \\
\text { statues }\end{array}$ & $\begin{array}{l}\text { Interventions } \\
\text { (Num) }\end{array}$ & $\begin{array}{l}\text { Median } \\
\text { observational } \\
\text { time (years) }\end{array}$ & $\begin{array}{l}\text { CVD/HHF- } \\
\text { Hazard } \\
\text { Ratio } \\
\text { (SGLT-2i } \\
\text { vs. } \\
\text { Placebo) }\end{array}$ & $\begin{array}{l}\text { HHF- } \\
\text { Hazard } \\
\text { Ratio } \\
\text { (SGLT-2i } \\
\text { vs. } \\
\text { Placebo) }\end{array}$ & $\begin{array}{l}\text { CVD- } \\
\text { Hazard } \\
\text { Ratio } \\
\text { (SGLT-2i } \\
\text { vs. } \\
\text { Placebo) }\end{array}$ \\
\hline Fitchett & 2016 & Empagliflozin & $\begin{array}{l}\text { NCT01131676 } \\
\text { (EMPA-REG } \\
\text { OUTCOME } \\
\text { trial) }\end{array}$ & 706 & all HF & $\begin{array}{l}\text { Empagliflozin } \\
10 \mathrm{mg} \text { or } \\
25 \mathrm{mg} \text { ( } 462 \\
\text { pts) } \\
\text { Placobo ( } 244 \\
\text { pts) }\end{array}$ & 3.1 & $\begin{array}{l}0.72(0.5- \\
1.04)\end{array}$ & $\begin{array}{l}0.75 \\
(0.48- \\
1.19)\end{array}$ & $\begin{array}{l}0.71 \\
(0.43- \\
1.16)\end{array}$ \\
\hline Kato & 2019 & Dapagliflozin & $\begin{array}{l}\text { NCTO1730534 } \\
\text { (DECLARE- } \\
\text { TIMI } 58 \text { trial) }\end{array}$ & 1987 & $\begin{array}{l}\text { HFrEF } \\
\stackrel{+}{\text { HFpEF }}\end{array}$ & $\begin{array}{l}\text { Dapagliflozin } \\
10 \mathrm{mg}(980 \\
\text { pts) } \\
\text { Placobo } \\
\text { (1007pts) }\end{array}$ & 4.2 & $\begin{array}{l}\text { HFrEF } \\
0.62 \\
(0.45- \\
0.86) \\
\text { HFpEF } \\
0.88 \\
(0.66- \\
1.17)\end{array}$ & $\begin{array}{l}\text { HFrEF } \\
0.64 \\
(0.43- \\
0.95) \\
\text { HFpEF } \\
0.72 \\
(0.50- \\
1.04)\end{array}$ & $\begin{array}{l}\text { HFrEF } \\
0.55 \\
(0.34- \\
0.90) \\
\text { HFpEF } \\
1.41 \\
(0.93- \\
2.13)\end{array}$ \\
\hline Petrie & 2020 & Dapagliflozin & $\begin{array}{l}\text { NCT03036124 } \\
\text { (DAPA-HF trial) }\end{array}$ & 2139 & HFrEF & $\begin{array}{l}\text { Dapagliflozin } \\
\text { 10mg } \\
\text { (1075pts) } \\
\text { Placobo } \\
\text { (1064 pts) }\end{array}$ & 1.5 & $\begin{array}{l}0.75 \\
(0.63- \\
0.90)\end{array}$ & $\begin{array}{l}0.76 \\
(0.61- \\
0.95)\end{array}$ & $\begin{array}{l}0.79 \\
(0.63- \\
1.01)\end{array}$ \\
\hline Rådholm & 2018 & Canagliflozin & $\begin{array}{l}\text { NCT01032629, } \\
\text { NCT01989754 } \\
\text { (CANVAS } \\
\text { Program) }\end{array}$ & 1461 & all HF & $\begin{array}{l}\text { Canagliflozin } \\
100 \mathrm{mg} \text { or } \\
300 \mathrm{mg}(803) \\
\text { placebo (658) }\end{array}$ & 3.6 & $\begin{array}{l}0.61 \\
(0.46- \\
0.80)\end{array}$ & $\begin{array}{l}0.51 \\
(0.33- \\
0.78)\end{array}$ & $\begin{array}{l}0.72 \\
(0.51- \\
1.02)\end{array}$ \\
\hline Sarraju & 2020 & Canagliflozin & $\begin{array}{l}\text { NCT02065791 } \\
\text { (CREDENCE } \\
\text { trial) }\end{array}$ & 652 & all HF & $\begin{array}{l}\text { Canagliflozin } \\
100 \mathrm{mg}(329) \\
\text { placebo }(323)\end{array}$ & 2.6 & $\begin{array}{l}0.81 \\
(0.57- \\
1.17)\end{array}$ & $\begin{array}{l}0.76 \\
(0.47- \\
1.22)\end{array}$ & NA \\
\hline
\end{tabular}

\section{Effect of SGLT-2 inhibitors on cardiovascular outcomes in patients with HF and T2DM}

All studies used HRs as a measure of effect size, which were estimated by Cox proportional hazards regression after adjusting for time effects. The metaanalysis of selected trials showed that SGLT-2 inhibitors significantly decreased the risk of primary outcome (composite of CVD/HHF) by $13 \%$ (pooled HR: $0.87,95 \% \mathrm{Cl}: 0.83-0.91, \mathrm{l}^{2}: 0 \%, \mathrm{P}<0.00001$, Figure $2 \mathrm{~A}$ ) in patients with $\mathrm{HF}$ and T2DM, and led to a statistically significant $14 \%$ reduction in $\mathrm{HHF}$ (pooled $\mathrm{HR}$ : $0.86,95 \% \mathrm{Cl}: 0.81-0.91, \mathrm{I}^{2}: 0 \%, \mathrm{P}<0.00001$, Figure $2 \mathrm{~B}$ ) while $10 \%$ reduction in ACM (pooled HR: 0.90, 95\% Cl: 0.86-0.96, I: 16\%, P<0.0005, Figure 2D). Although there was no significant difference between the effect of SGLT-2i and the effect of placebo on cardiovascular death (CVD), SGLT-2i showed a strong trend toward preventing CVD (pooled HR: 0.91, 95\% Cl: 0.81-1.02, I2: 60\%, P=0.11, Figure 2C).

\section{Sensitivity analysis}

Considering the possible bias introduced by the CREDENCE trial, whose data were presented at a conference, a sensitivity analysis was performed by removing this article to decrease heterogeneity and increase the reliability of the estimated treatment effect. The pooled meta-analysis data showed very consistent results (supplementary Figure 1) with the aforementioned results.

Alternatively, the DECLARE-TIMI 58 trial[9], DAPA-HF trial[11] and EMPA-REG OUTCOME trial[12] reported the frequency of different outcomes in the treatment and placebo groups. We thus extracted the data (supplementary table 1), and conducted a meta-analysis to further examine the association between SGLT-2 inhibitors and cardiovascular outcomes. Pooled data from the included studies demonstrated that patients with HF and T2DM who received SGLT-2 inhibitors had a remarkably lower incidence rate of primary cardiovascular outcomes (weighted proportions: $17.4 \%$ vs $22.1 \%$; RR $0.79,95 \% \mathrm{Cl} 0.71-0.89$, $\mathrm{p}<0.0001$; Figure $3 \mathrm{~A}$ ), hospitalization for heart failure (weighted proportions: $10.9 \%$ vs $13.9 \%$; RR $0.77,95 \% \mathrm{Cl} 0.67-0.90, \mathrm{p}=0.0009$; Figure $3 \mathrm{~B}$ ) and all-cause mortality (weighted proportions: $12.8 \%$ vs $15.6 \%$; RR $0.82,95 \% \mathrm{Cl} 0.71-0.94, \mathrm{p}=0.005$; Figure $3 \mathrm{D}$ ). Likewise, the risk of cardiovascular death tended to be lower in the SGLT-2i group than in the placebo group; however, this difference was not significant (weighted proportions: $9.6 \%$ vs $11.2 \%$; RR $0.85,95 \%$ CI $0.72-1.00$, $p=0 \cdot 05$; Figure $3 C)$.

\section{Safety outcome}

Serious AEs were considered the safety outcome in this meta-analysis, and the incidence rate was reported in three trials[9, 11, 12]. The relatively common adverse events of interest were volume depletion and kidney impairment (less than 10\%), but the incidence of these adverse events did not differ significantly between the SGLT-2i and placebo groups. More intriguingly, compared with the placebo group, the SGLT-2i group reported a lower proportion of serious adverse events (weighted proportions: $44.3 \%$ vs $50.3 \%$; RR 0.88, 95\% Cl 0.82-0.95, p=0•006; Figure 4).

Risk of bias assessment 
The risk of bias was low for all RCTs except for two studies[10,13], in which incomplete data indicated an attrition bias (unclear risk). One study had an unclear risk of reporting bias because of a lack of peer-reviewed, full-text data[13] (Supplementary Figure 2). Overall, the statistical heterogeneity of all the outcomes assessed by the $\mathrm{I}^{2}$ test was very low (the majority of $\mathrm{I}^{2}$ values were less than $25 \%$ ). Visual and formal analyses of funnel plots did not suggest any risk of publication bias (Supplementary Figure 3).

\section{Discussion}

In this meta-analysis, we evaluated large-scale trials of HF patients with T2DM that compared the effect of SGLT-2 inhibitors vs. placebo on clinical cardiovascular outcomes. Overall, SGLT-2 inhibitors significantly reduced the risk of the primary outcome, namely, the composite of CVD/HHF, by $13 \%$ (pooled HR: $\left.0.87,95 \% \mathrm{Cl}: 0.83-0.91, \mathrm{I}^{2}: 0 \%, \mathrm{P}<0.00001\right)$. The risk of HHF and the risk of ACM were also decreased by $14 \%$ and $10 \%$ in the SGLT-2i group, respectively. Of note, the effect of SGLT-2i on CVD was not significant (pooled HR: $0.91,95 \% \mathrm{Cl}: 0.81-1.02,1^{2}: 60 \%, \mathrm{P}<0.11$ ). Thus, the cardiovascular protective role of SGLT-2i in a broad range of HF patients concomitant with T2DM seems to be greatly contributed to the effect of preventing HHF.

The biological mechanisms underlying the effect of SGLT-2 inhibitors on HF remain largely unknown. SGLT-2i mediated natriuresis and glucosuria would be one of the most important interpretations, which contribute to lower cardiac pre-load and reduce pulmonary congestion and systemic oedema[17, 18]. Additional suggested mechanisms to explain the benefits of SGLT-2i include improved tissue oxygenation owing to increased haematocrit (by stimulating renal erythropoietin secretion) and a cardioprotective state related to the inhibition of myocardial sodium-hydrogen transporter[19]. Moreover, it has been suggested that SGLT-2i alters fuel consumption with an increase in oxidation of fatty acids and ketogenesis and with a concomitant reduction in the utilization of carbohydrates. These alterations resulted in an approximately $30 \%$ increase in the cardiac production of ATP and greatly improved cardiac metabolism[20]. The cardio-protective effects of SGLT-2i are most likely multifactorial and need to be further explored.

Of interest, the 5 included clinical trials have a broad spectrum of HF patients, including heart failure with reduced ejection fraction (HFrEF) and heart failure with preserved ejection fraction (HFpEF); however, the DAPA-HF study enrolled only HFrEF patients. It was estimated that the reduction of the risk of both mortality and the primary outcome (the composite of CVD/HHF) may vary directly with the severity of the disorder. Thus, the DAPA-HF study, which included the largest fraction of patients who were NYHA functional class II-III (approximately 90\%), exhibited greater benefit for SGLT-2i than the CREDENCE trial and the EMPA-REG OUTCOME trial. More interestingly, the DECLARE-TIMI 58 trial showed that dapagliflozin reduced cardiovascular death/HHF events to a greater extent in patients with HFrEF ( $\mathrm{HR} \mathrm{0.62,95 \%} \mathrm{Cl} 0.45-0.86)$ than in those with HFpEF (HR 0.88, 95\% Cl 0.66-1.17; P for interaction = 0.046). In our metaanalysis, the pooled data comprising a total of 6945 patients with HF and T2DM demonstrated favourable HF outcomes associated with the use of SGLT-2 inhibitors, which represented an overall effect of SGLT-2 inhibitors in a broad spectrum of patients with HF and concomitant T2DM.

All the included studies used HRs to estimate the effect size. In this meta-analysis, we favoured HRs obtained from Cox regression analyses as the key results, to adjust for as many confounding factors as possible, including age, sex, time to events, or other medical variables. In addition, 3 articles reported the incidence rate and sample size of outcomes. Then, in our sensitivity analysis, relative data were extracted and pooled using the Mantel-Haenszel method. The SGLT-2i group had a markedly lower incidence rate of the composite of CVD/HHF than the placebo group (weighted proportion $17.4 \%$ vs $22.1 \%$; RR $0.79,95 \%$ $\mathrm{Cl} 0.71-0.89, \mathrm{p}<0.0001)$. Additionally, a subgroup analysis from a recently published meta-analysis displayed a similar superior effect of SGLT-2i over the use of a placebo[21]. However, our meta-analysis substantially expands on that study by adding two more clinical trials (total of 5 studies) and incorporating more key outcomes. From the primary and sensitivity analyses in our study, we clearly demonstrated that SGLT-2 inhibitors significantly reduced the relative risk of the composite of CVD/HHF outcome (CVD/HHF), HHF alone, and all-cause mortality in patients with HF and T2DM. However, we only observed a nonsignificant trend of SGLT-2i decreasing the risk of cardiovascular death. The safety profile was similar between the SGLT-2i group and the placebo group, with comparable incidence rates of volume depletion and kidney impairment[11]. Meta-analysis of the available literature even displayed a favourable safety outcome of serious adverse events in the SGLT-2i group (weighted proportions: $44.3 \%$ vs $50.3 \%$; RR 0.88, 95\% Cl 0.82-0.95, p = 0.006).

It is also important to acknowledge some limitations of our study. First, only 5 clinical trials were enrolled in this meta-analysis, which represented a relatively small size for pooling data. However, the heterogeneity for outcomes, as assessed by the $\mathrm{l}^{2}$ statistic, showed very low heterogeneity across all the studies. The consistency of the treatment effects across sensitivity analyses was also reassuring. Thus, the results drawn from this study are credible. Additionally, the baseline presence of heart failure was investigator-reported in all trials except for the DAPA-HF trial. The definition of inclusion criteria would be slightly different. Last, although our study is based on pre-specified analyses of RCTs, HF patients may not have been totally randomized with respect to disease severity, disease duration or medications used. Fortunately, several ongoing trials are directly investigating the role of SGLT-2i in HF patients with and without T2DM[22-25]. The results of these clinical trials are eagerly awaited and would help broaden our understanding of the clinical benefits of SGLT-2i for the treatment and prevention of HF.

\section{Conclusions}

The present meta-analysis demonstrated that SGLT-2 inhibitors significantly reduced the risk for the composite of CVD/HHF by $13 \%$ in a broad range of HF patients concomitant with T2DM. Moreover, SGLT-2 inhibitors were found to be robustly effective in reducing the risks of hospitalization for heart failure and all-cause mortality but not in reducing the risks of cardiovascular death. Although they were initially considered to be glucose-lowering agents, the effects of SGLT-2i have expanded far beyond that, and they are now being studied as a treatment for heart failure. Further dedicated prospective randomized studies are warranted to investigate the efficacy and safety of SGLT-2i on heart failure.

\section{Abbreviations}


heart failure; T2DM:type 2 diabetes mellitus; SGLT2i:sodium-glucose cotransporter-2 inhibitors; HFrEF:heart failure with reduced ejection fraction; HFpEF:heart failure with preserved ejection fraction; CVD:cardiovascular death; HHF:hospitalization for heart failure, ACM:all-cause mortality; Cl:confidence interval.

\section{Declarations}

Ethics approval and consent to participate

Not applicable.

\section{Availability of data and materials}

The data that support the findings of this study are available from the corresponding author upon reasonable request.

\section{Consent for publication}

Not applicable.

\section{Conflict of Interest}

The authors declare no conflict of interest.

\section{Disclosure of Funding}

This work was supported by National Natural Science Foundation of China (Grant No. 81700231) and Bringing in talent for clinical medicine expert project of Xuzhou City, Jiangsu Province.

\section{Author Contributions}

Drs J.X and ML.C contributed to study concept and design, data interpretation, and draft revising. Drs Y.L, Y.Y, CZ.L and Y.D contributed to acquisition of data, quality assessment, and data analysis. Drs Y. F contributed to the design of statistical analyses and interpretation of data. Drs Y.L and Y.Y wrote the first draft of the report. Drs ZR.W contributed to draft revising. Drs M.Z and L.C contributed critical revision of the manuscript for important intellectual content. All authors have approved the final version to be published.

\section{Acknowledgement}

Not applicable.

\section{References}

1. Braunwald $\mathrm{E}$ : The war against heart failure: the Lancet lecture. Lancet 2015, 385(9970):812-824.

2. Bloom MW, Greenberg B, Jaarsma T, Januzzi JL, Lam CSP, Maggioni AP, Trochu J-N, Butler J: Heart failure with reduced ejection fraction. Nature Reviews Disease Primers 2017, 3(1):17058.

3. McMurray JJ, Packer M, Desai AS, Gong J, Lefkowitz MP, Rizkala AR, Rouleau JL, Shi VC, Solomon SD, Swedberg K et al: Angiotensin-neprilysin inhibition versus enalapril in heart failure. The New England journal of medicine 2014, 371(11):993-1004.

4. Swedberg K, Komajda M, Bohm M, Borer JS, Ford I, Dubost-Brama A, Lerebours G, Tavazzi L, Investigators S: Ivabradine and outcomes in chronic heart failure (SHIFT): a randomised placebo-controlled study. Lancet 2010, 376(9744):875-885.

5. Sharma A, Zhao X, Hammill BG, Hernandez AF, Fonarow GC, Felker GM, Yancy CW, Heidenreich PA, Ezekowitz JA, DeVore AD: Trends in Noncardiovascular Comorbidities Among Patients Hospitalized for Heart Failure Insights From the Get With The Guidelines-Heart Failure Registry. Circ-Heart Fail 2018, 11(6).

6. Cubbon RM, Adams B, Rajwani A, Mercer BN, Patel PA, Gherardi G, Gale CP, Batin PD, Ajjan R, Kearney L et al: Diabetes mellitus is associated with adverse prognosis in chronic heart failure of ischaemic and non-ischaemic aetiology. Diab Vasc Dis Res 2013, 10(4):330-336.

7. Zinman B, Wanner C, Lachin JM, Fitchett D, Bluhmki E, Hantel S, Mattheus M, Devins T, Johansen OE, Woerle HJ et al: Empagliflozin, cardiovascular outcomes, and mortality in type 2 diabetes. New england journal of medicine 2015, 373(22):2117-2128.

8. Neal B, Perkovic V, Mahaffey KW, de Zeeuw D, Fulcher G, Erondu N, Shaw W, Law G, Desai M, Matthews DR et al: Canagliflozin and Cardiovascular and Renal Events in Type 2 Diabetes. The New England journal of medicine 2017, 377(7):644-657.

9. Kato ET, Silverman MG, Mosenzon O, Zelniker TA, Cahn A, Furtado RHM, Kuder J, Murphy SA, Bhatt DL, Leiter LA et al: Effect of Dapagliflozin on Heart Failure and Mortality in Type 2 Diabetes Mellitus. Circulation 2019, 139(22):2528-2536.

10. Rådholm K, Figtree G, Perkovic V, Solomon SD, Mahaffey KW, de Zeeuw D, Fulcher G, Barrett TD, Shaw W, Desai M et al: Canagliflozin and Heart Failure in Type 2 Diabetes Mellitus: results From the CANVAS Program. Circulation 2018, 138(5):458-468.

11. Petrie MC, Verma S, Docherty KF, Inzucchi SE, Anand I, Belohlavek J, Bohm M, Chiang CE, Chopra VK, de Boer RA et al: Effect of Dapagliflozin on Worsening Heart Failure and Cardiovascular Death in Patients With Heart Failure With and Without Diabetes. JAMA 2020.

12. Fitchett D, Zinman B, Wanner C, Lachin JM, Hantel S, Salsali A, Johansen OE, Woerle HJ, Broedl UC, Inzucchi SE: Heart failure outcomes with empagliflozin in patients with type 2 diabetes at high cardiovascular risk: results of the EMPA-REG OUTCOME® trial. European heart journa/2016, 37(19):1526-1534. 
13. Sarraju A, Li J, Cannon CP, Chang TI, Agarwal R, Bakris GL, Charytan DM, de Zeeuw D, Greene T, Heerspink HJL et al: Canagliflozin (Cana) Reduces Cardiovascular (Cv) and Renal Events Independent of Baseline Heart Failure (Hf): A Credence Secondary Analysis. Journal of the American College of Cardiology 2020, 75(11):1018.

14. Moher D, Liberati A, Tetzlaff J, Altman DG, Grp P: Preferred Reporting Items for Systematic Reviews and Meta-Analyses: The PRISMA Statement. Plos Med 2009, 6(7).

15. Hartung JK, G. and Sinha, B.K.: Combining Controlled Trials with Discrete Outcomes; 2008.

16. Higgins JP, Thompson SG, Deeks JJ, Altman DG: Measuring inconsistency in meta-analyses. BMJ 2003, 327(7414):557-560.

17. Hallow KM, Helmlinger G, Greasley PJ, McMurray JJV, Boulton DW: Why do SGLT2 inhibitors reduce heart failure hospitalization? A differential volume regulation hypothesis. Diabetes, obesity \& metabolism 2018, 20(3):479-487.

18. Zelniker TA, Braunwald E: Mechanisms of Cardiorenal Effects of Sodium-Glucose Cotransporter 2 Inhibitors JACC State-of-the-Art Review. Journal of the American College of Cardiology 2020, 75(4):422-434.

19. Uthman L, Baartscheer A, Bleijlevens B, Schumacher CA, Fiolet JWT, Koeman A, Jancev M, Hollmann MW, Weber NC, Coronel R et al: Class effects of SGLT2 inhibitors in mouse cardiomyocytes and hearts: inhibition of $\mathrm{Na}+\mathrm{H}+$ exchanger, lowering of cytosolic Na+ and vasodilation. Diabetologia 2018 , 61(3):722-726

20. Verma S, Rawat S, Ho KL, Wagg CS, Zhang L, Teoh H, Dyck JE, Uddin GM, Oudit GY, Mayoux E et al: Empagliflozin Increases Cardiac Energy Production in Diabetes: Novel Translational Insights Into the Heart Failure Benefits of SGLT2 Inhibitors. JACC: Basic to Translational Science 2018, 3(5):575-587.

21. Zelniker TA, Wiviott SD, Raz I: SGLT2 inhibitors for primary and secondary prevention of cardiovascular and renal outcomes in type 2 diabetes: a systematic review and meta-analysis of cardiovascular outcome trials. Lancet 2019, 393(10166):30-30.

22. Ejiri K, Miyoshi T, Nakamura K, Sakuragi S, Munemasa M, Namba S, Takaishi A, Ito H: The effect of luseogliflozin and alpha-glucosidase inhibitor on heart failure with preserved ejection fraction in diabetic patients: rationale and design of the MUSCAT-HF randomised controlled trial. BMJ open 2019 , 9(3):e026590.

23. Jensen J, Omar M, Kistorp C, Poulsen MK, Tuxen C, Gustafsson I, Kober L, Gustafsson F, Fosbol E, Bruun NE et al: Empagliflozin in heart failure patients with reduced ejection fraction: a randomized clinical trial (Empire HF). Trials 2019, 20(1):374.

24. Anker SD, Zannad F, Butler J, Filippatos G, Salsali A, Kimura K, Schnee J, Zeller C, Pocock S, George JT et al: Design and rationale of the EMPEROR trials of empagliflozin in patients with chronic heart failure with reduced or preserved ejection fraction. Diabetologia 2018, 61:S324-

25. Abraham WT, Ponikowski P, Brueckmann M, Zeller C, Macesic H, Peil B, Brun M, Ustyugova A, Jamal W, Salsali A et al: Rationale and design of the EMPERIAL-Preserved and EMPERIAL-Reduced trials of empagliflozin in patients with chronic heart failure. European journal of heart failure 2019, 21(7):932-942.

\section{Figures}




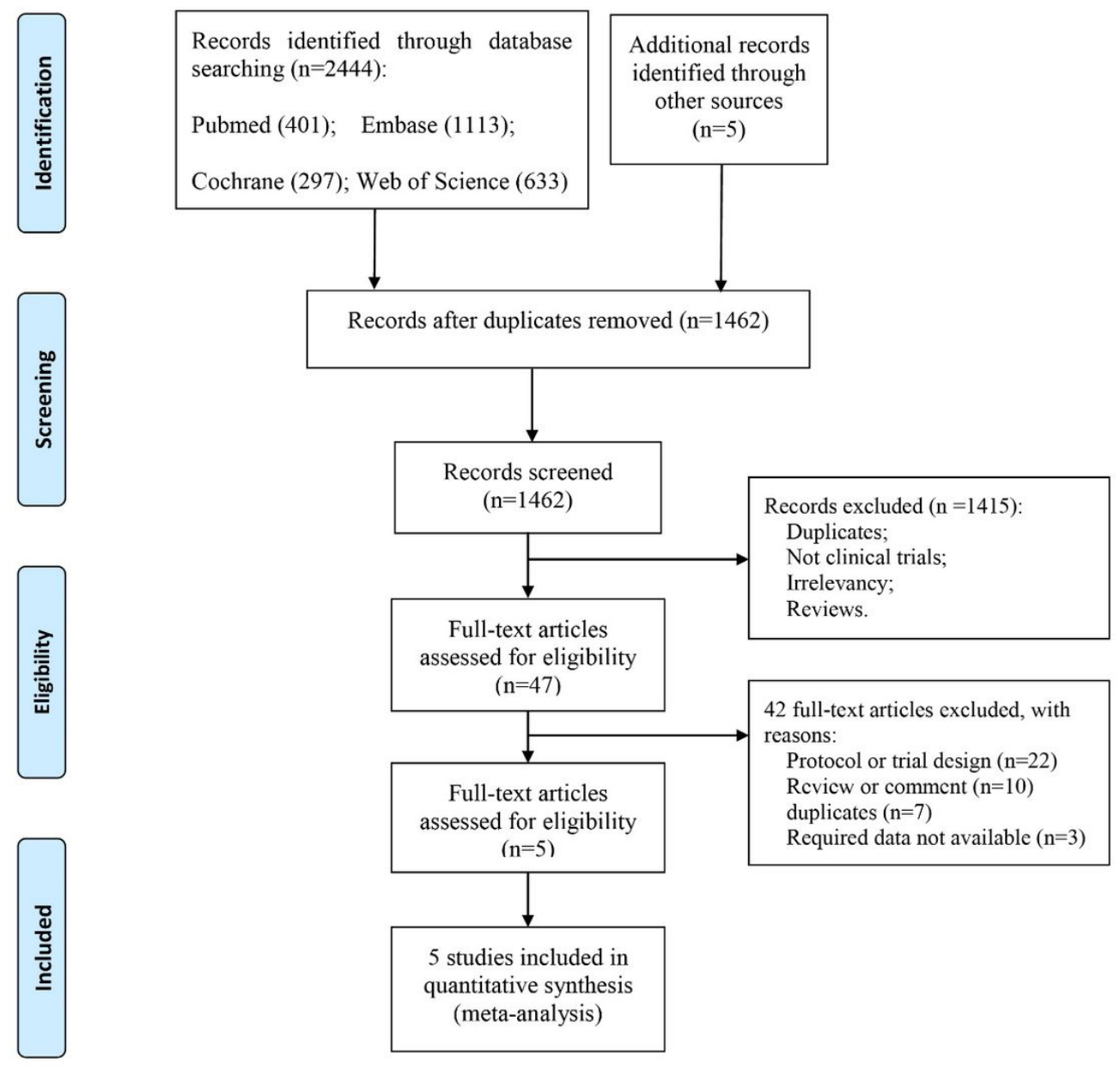

Figure 1

Study flow chart of the article identification, inclusion, and exclusion. 


\section{A}

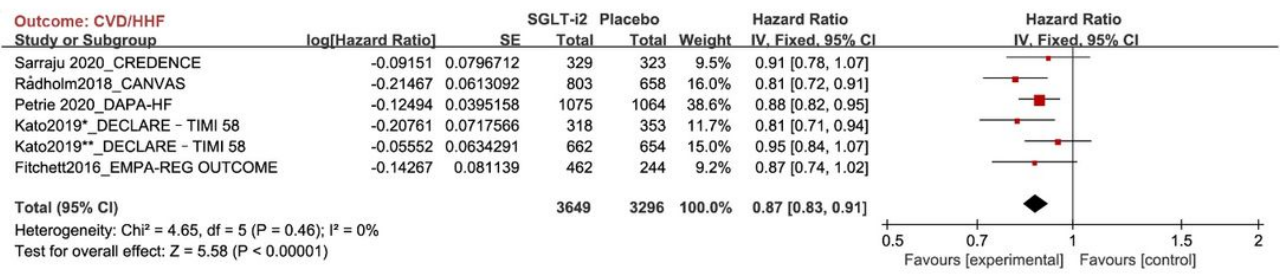

Heterogeneity: Chi ${ }^{2}=4.65, \mathrm{df}=5(P=0.46) ;$
Test for overall effect: $Z=5.58(P<0.00001)$

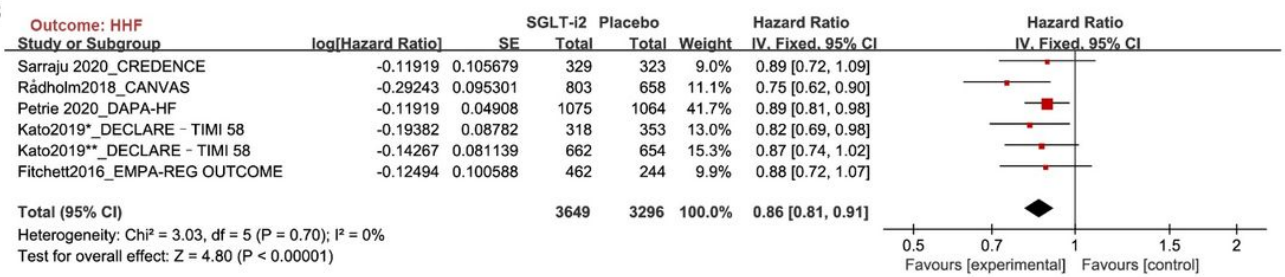

C Outcome: CVD

SGLT-i2 Placebo Hazard Ratio

Ràdholm2018 CANVAS

Petrie 2020_DAPA-HF

Kato2019*_DECLARE - TIMI 58

Kato2019**_DECLARE - TIMI 58

Fitchett2016_EMPA-REG OUTCOME

Total $(95 \% \mathrm{Cl})$

Heterogeneity: Tau $^{2}=0.01 ; \mathrm{Chi}^{2}=10.05, \mathrm{df}=4(\mathrm{P}=0.04) ; \mathrm{I}^{2}=60 \%$
Test for overall effect: $Z=1.62(P=0.11)$ log[Hazard Ratio] SE Total Total Weight IV. Random. 95\%

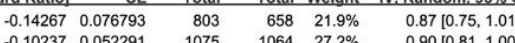

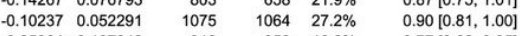

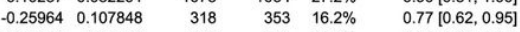
$\begin{array}{llllll}0.149219 & 0.09181 & 662 & 654 & 18.9 \% & 1.16[0.97,1.39]\end{array}$

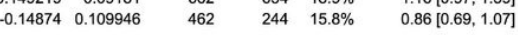

$3320 \quad 2973 \quad 100.0 \% \quad 0.91[0.81,1.02]$

D Outcome: ACM

SGLT-i2 Placebo Hazard Ratio \begin{tabular}{lrrrrrr} 
Study or Subgroup & leg[Hazard Ratio] & SE & Total & Total Weight & IV. Fixed. 95\% \\
\hline Sarraju 2020_CREDENCE & -0.03152 & 0.092829 & 329 & 323 & $9.5 \%$ & $0.97[0.81,1.16$
\end{tabular}

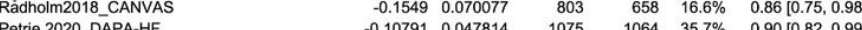

Petrie 2020_DAPA-HF

$\begin{array}{rrrrrr}0.10791 & 0.047814 & 1075 & 1064 & 35.7 \% & 0.90[0.82,0.99\end{array}$

Kato2019*-DECLARE - TIMI 58

Fitchett2016 EMPA-REG OUTCOME

0.00860 .067556

$\begin{array}{llll}318 & 353 & 10.7 \% & 0.80[0.67,0.94]\end{array}$

$\begin{array}{llll}662 & 654 & 17.9 \% & 1.01[0.88,1.1\end{array}$

$\begin{array}{llll}3649 & 3296 & 100.0 \% & 0.90\end{array}[0.86,0.96]$

Total $(95 \% \mathrm{Cl})$

$0.10237 \quad 0.092647$

Heterogeneity: $\mathrm{Chi}^{2}=5.96, \mathrm{df}=5(P=0.31) ; \mathrm{I}^{2}=16 \%$

Heterogeneity: Chi ${ }^{2}=5.96, d f=5(P=0.31)$
Test for overall effect: $Z=3.50(P=0.0005)$

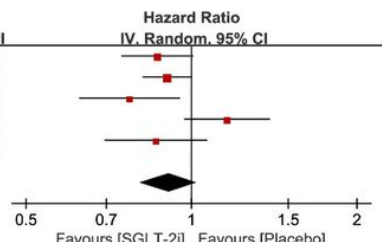

\section{Figure 2}

Effect of SGLT-2i on the composite of CVD/HHF (A), HHF (B), CVD (C) and ACM (D) in patients with HF and T2DM assessed by the generic inverse variance method. The data of the DECLARE-TIMI 58 trial were divided into two parts: heart failure with reduced ejection fraction (HFrEF) and heart failure with preserved ejection fraction (HFpEF). *represents HFrEF patients; **represents HFpEF patients. Abbreviation SGLT2i: sodium-glucose cotransporter-2 inhibitors; CVD: cardiovascular death; HHF: hospitalization for heart failure, ACM: all-cause mortality; Cl: confidence interval. 
A

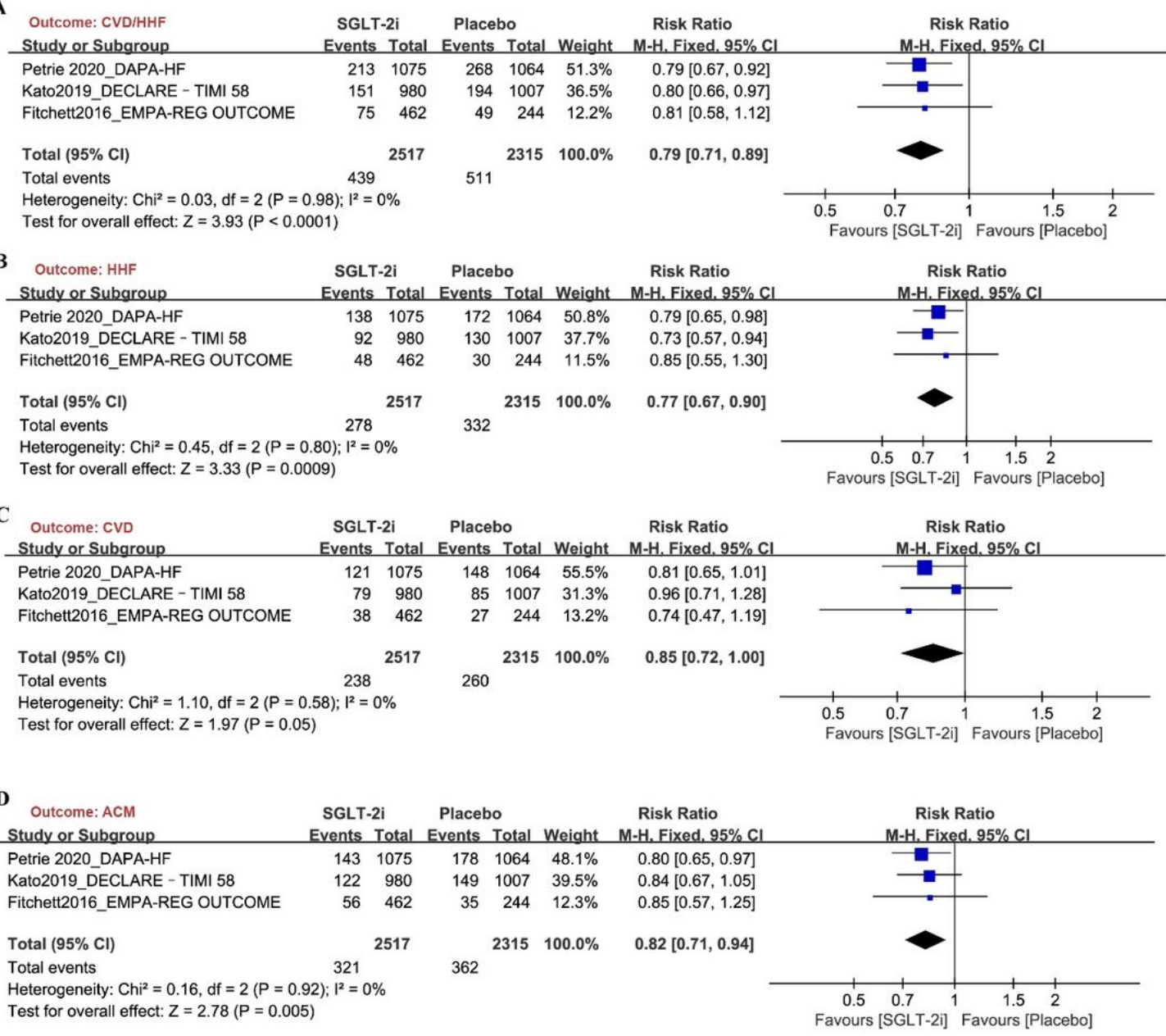

\section{Figure 3}

Sensitivity analysis: effect of SGLT-2i on the composite of CVD/HHF (A), HHF (B), CVD (C) and ACM (D) in patients with HF and T2DM assessed by the Mantel-Haenszel method. Abbreviation SGLT2i: sodium-glucose cotransporter-2 inhibitors; CVD: cardiovascular death; HHF: hospitalization for heart failure, ACM: all-cause mortality; Cl: confidence interval.

\begin{tabular}{|c|c|c|c|c|c|c|c|c|}
\hline Study or Subgroup & SGLT-2i & $\begin{array}{l}2 i \\
\text { Total }\end{array}$ & $\begin{array}{l}\text { Placeb } \\
\text { Events }\end{array}$ & Total & Weight & $\begin{array}{l}\text { Risk Ratio } \\
\text { M-H. Fixed. } 95 \% \mathrm{Cl}\end{array}$ & \multicolumn{2}{|c|}{$\begin{array}{c}\text { Risk Ratio } \\
\text { M-H. Fixed. } 95 \% \mathrm{Cl} \\
\end{array}$} \\
\hline Kato $2019^{*}$ DECLARE - TIMI 58 & 172 & 317 & 196 & 353 & $21.4 \%$ & $0.98[0.85,1.12]$ & & \\
\hline Total $(95 \% \mathrm{Cl})$ & & 1852 & & 1660 & $100.0 \%$ & $0.88[0.82,0.95]$ & & \\
\hline Total events & 821 & & 835 & & & & & \\
\hline $\begin{array}{l}\text { Heterogeneity: } \mathrm{Ch}^{2}=2.56, d f=2(P= \\
\text { Test for overall effect: } Z=3.43(P=0.0\end{array}$ & $\begin{array}{l}28) ; 1^{2}=22 \\
\text { (6) }\end{array}$ & & & & & & 0.7 & 1.2 \\
\hline
\end{tabular}

\section{Figure 4}

Meta-analysis of serious adverse events in the SGLT-2i group and placebo group. Abbreviation SGLT2i: sodium-glucose cotransporter-2 inhibitors; Cl: confidence interval.

\section{Supplementary Files}

This is a list of supplementary files associated with this preprint. Click to download. 
- SupplementarytableandFigures.docx

Page 11/11 